\title{
Study on Laser beam Welding of Copper and Aluminum joint
}

\author{
R.S. Chopde ${ }^{1,2}$, S.P. Gadewar ${ }^{1}$, M.P. Khond ${ }^{3}$, M.J . Rathod ${ }^{4}$ \\ ${ }^{\text {I}}$ (Department of Mechanical Engineering, M.E.S College of Engineering, S.P. Pune university, Pune India, \\ ${ }^{2}$ (John Deere India Pvt. ltd, Pune India) \\ ${ }^{3}$ (Department of Mechanical Engineering, College of Engineering, S.P. Pune University, India) \\ ${ }^{4}$ (Department of Material science and Metallurgy, College of Engineering, Pune, India)
}

\begin{abstract}
Aluminum and Copper has more significance in electrical and electronic application such as solar energy collectors or light weight electric motors and actuators. It combines comparably good thermal and electrical properties with attractive price and low material weight. However the main difficulty for widespread use of aluminum is the lack of reliable joining process to connect it with copper. The Intermetallic formation during welding of copper and aluminum are caused by large misalignment in physical properties and even more poor metallurgical affinity of both materials and therefore crack sensitivity and formation of brittle intermetallic phase during fusion welding. Wide range of materials can be welded by laser, especially the alloys that are normally difficult to weld by conventional welding. Since absorption of the laser power is crucial for melting, conductivity and reflectivity are important key factors for achieving better melting. In this effort we have investigated laser welding of aluminum and copper of $2 \mathrm{~mm}$ thick with literature studies in past. This paper also concentrates on review of current processes for joining Aluminum and copper with disadvantages and feasibility of laser welding the same metals with higher efficiency.
\end{abstract}

Keywords: Laser Welding, Copper and Aluminum

\section{Introduction}

Generally aluminum is a reactive material that oxidizes easily, but in practice it has proved to offer good corrosion resistance. This characteristic is due to a chemical reaction that takes place when in contact with atmospheric oxygen resulting in a very thin but also very resistant oxide layer being formed. When metals are connected to those with a higher electrical potential such as copper in the presences of an electrolyte (condensed water) will result in an electrochemical reaction taking place. During this process the differences caused in electrochemical potential can have a significant impact. Connection has its needs in batteries and electrical transformation. The unique combination of light weight and relatively high strength makes aluminum the second most popular metal that is welded. Application of Copper and Aluminum joint includes cable lugs, electromagnetic coils, medical devices, batteries and jointing clamp wire terminals, PCBs, CRTs, transformer plates and accumulator plates Aluminum is not difficult to join but aluminum welding is different from welding copper. Major objective of this study is to,

- Current welding processes for Al-Cu weld joint and issues

- Compatibility between copper and Aluminum

- Evaluate Laser welding parameters for optimum joint efficiency between dissimilar metals Copper and Aluminium

- Using factorial design approach statistical design of experiment (DOE) technique for optimizing the selected welding parameters in terms of maximizing tensile strength using statistical software Minitab.

Further aluminum and Copper weld will be evaluated for its strength with laser welding. It will be followed by microstructural analysis of joint for further study and conclusion on efficiency of welding. Hailat, et al. [1] has experimented continuous laser welding of two dissimilar materials, aluminum and copper, was investigated. The aluminum and the copper utilized were Al3003-H14 and Cu110-H00, respectively. The foil alloy was utilized to enhance the compatibility of the two metals; aluminum and copper, reducing the brittleness of the intermetallic compound that may form and, subsequently, enhance the mechanical properties. Samples in which filler foil was used exhibited a better performance in the lap shear stress test (an average of $780 \mathrm{~N}$ ) than the samples without tin foil (an average of $650 \mathrm{~N}$ ). The improvement in the lap shear test could be attributed to the positive effects of the filler on enhancing the compatibility of the intermetallic compound formed via diffusion. The failure mechanism predicted from the FE model matches reasonably well with the experimental observations from EDAX analysis. Mai, et al [2] presents the results of an investigation into laser welding of dissimilar metals without filler materials using a 350W pulsed Nd:YAG laser. Two etchants were developed to 
reveal the microstructure of the welds. Examination of the porosity showed clear trends associated with welding speed. The weldability of copper to aluminum is regarded as relatively good. The $\mathrm{Cu}-\mathrm{Al}$ phase diagram shows a wide range of $\mathrm{Cu}-\mathrm{Al}$ phases that may be formed. In addition, non-equilibrium cooling conditions are known to promote the formation of a cascade of metasTable phases. Under optimum processing parameters, crack-free welds of copper and Al 4047 were obtained. Attempts to weld copper with aluminum alloy 6061, a heat-treated $\mathrm{Al}-\mathrm{Mg}-\mathrm{Si}-\mathrm{Cu}$ alloy with high mechanical strength, were not successful due to its poor weldability and high crack susceptibility Tadamalle, et al [3] aimed at to examine the influence of welding speed and power on weld bead geometry and performance parameters such as duty cycle, pulse overlap, energy density and bead diameter. The solidification time in this process is very less as compared to that of conventional welding process. The mode of welding process is governed by the process parameters like laser energy, pulse duration, pulse frequency, power and welding speed. In this contest, first experiment is conducted on austenitic 304L stainless steel sheet by varying the welding speed from $2 \mathrm{~mm} / \mathrm{s}$ to $10 \mathrm{~mm} / \mathrm{s}$ and second experiment is conducted varying laser power from $300 \mathrm{~W}$ to $3500 \mathrm{~W}$. It was found from the experimental and analytical approach welding speed and laser power significantly effects on weld bead geometry, variation in bead diameter from pulse to pulse, duty cycle and effective pulse energy. Kim, et al [4] presents a systematic approach to determine optimal process parameters associated with Hybrid welding using Taguchi Method. Plate of aluminum alloy (AA502-H32) of square grove is considered for welding butt joint. In order to compare weld ability of each experimental group, ultimate tensile strength (UTS) is chosen. Welding experiment is repeated three times under same conditions. Even though process was carried out identically, result of strength test could be different due to correlation of each parameter and environmental factor. Strength data were used to compute performance characteristics of parametric combination for welding through calculation of signal to noise ratio. Kalaiselvan, et al [5] present study is to reviews the influence of different parameters like laser power, welding speed, power density, beam diameter, focusing distance and type of shielding gas on the mechanical properties of dissimilar metal combinations like SS/Al, $\mathrm{Cu} / \mathrm{Al}$ and $\mathrm{Ti} / \mathrm{Al}$ focusing on aluminum to other materials. Discussion has been documented about the effect of different parameters on LBW. They are, Laser Power, P(KW), LBW Welding Speed, V (mm/min), LBW Power Density (W/cm2), Beam Diameter, LBW Focal Distance, f (mm), LBW Shielding Gas Flow, V (1/min).

\section{Material Properties}

\section{Material Properties And Compatibility}

Materials used are Aluminum 6061T651. Each plate of aluminum is $70 \mathrm{~mm}$ length $\mathrm{x} 70 \mathrm{~mm}$ wide $\mathrm{x} 2$ $\mathrm{mm}$ thick. Chemical composition for each plate is as follows- Al,95.8-98.6\%; Cr. 0.04-0.35; $\mathrm{Cu} 0.15-04 ; \mathrm{Si}, 0.4-$ 08; Fe, Max 0.7; Zn, $0.25 \mathrm{max}, \mathrm{Mg}, 0.8-1.2$. Mechanical properties of same are as- Density: $2.7 \mathrm{~g} / \mathrm{cm}^{3} ; \mathrm{Melting}$ Point: Approx. $580^{\circ} \mathrm{C}$; Modulus of Elasticity: 70-80 GPa; Poisson Ratio: 0.33; Electrical Resistivity: 3.7 - 4.0

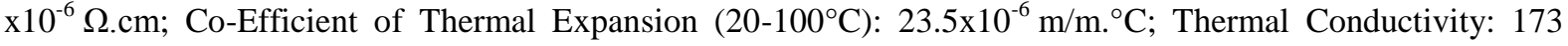
W/m.K. Ultimate Tensile Strength (MPa), 260-310; 0.2\%Proof Stress (MPa), 240-276 ; BrinellHardness (500kg load, 10mm ball); Elongation 50mm dia (\%), 95-97.

Material composition for Copper grade UNS C10100 is $\mathrm{Cu}, 99.99 \%$; $\mathrm{Ph}, 0.0003 \mathrm{Max}$; Trellurium, $0.001 \mathrm{max}$. Each plate of Copper is $70 \mathrm{~mm}$ ling x $70 \mathrm{~mm}$ wide x $2 \mathrm{~mm}$ thick. Copper specific grade selected for the purpose lower phosphorous content helps reduces oxidation of metal. Mechanical properties of selected grade is Density (lb / cu. in.)0.32; 3Electrical Resistivity (microhm-cm (at 68 Deg F)) 10.3; Melting Point (Deg F),198;Thermal Conductivity, 226; Mean Coeff Thermal Expansion, 9.4; Modulus of Elasticity Tension 17000 .

\section{Compatibility of aluminum with copper}

Both aluminum and copper will oxidize when exposed to the atmosphere. Aluminum and copper conductors are typically plated with silver or tin. The Density of aluminum is about one third of that of copper for equal conductance the weight of the aluminum conductor material is almost halved. Moisture is a source of hydrogen which is the cause of porosity in aluminum welds. With a rapid cooling rate free hydrogen is retained within the weld and will cause porosity. Porosity will decrease weld strength and ductility depending on the amount. The aluminum oxide film must be removed prior to welding. If it is not all removed small particles of un-melted oxide will be entrapped in the weld pool and will cause a reduction in ductility, lack of fusion, and may cause weld cracking. Copper has a relatively high coefficient of thermal expansion, approximately 50\% higher than carbon steel, but lower than aluminum. One of the problems associated with copper alloys is the fact that some of them, such as aluminum bronze, have a coefficient of expansion over $50 \%$ greater than that of copper. Some of the copper alloys are hot short. This means that they become brittle at high temperatures. This is because some of the alloying elements form oxides and other compounds at the grain boundaries, embrittling the material. There is one other problem associated with the copper alloys that contain zinc. Zinc has a relatively 
low boiling temperature, and under the heat of an arc will tend to vaporize and escape from the weld. For this reason the arc processes are not recommended for the alloys containing zinc. The primary difficulties with copper are the high reflectivity to the incident laser beam and the high thermal conductivity of copper and copper alloys. Copper reflects approximately 99 percent of the incident light energy the fast infrared wavelength of the $\mathrm{CO} 2$ laser. This is the reason copper is commonly used for mirrors in co3 laser beams deliver system. Reflectivity id temperature dependent; when then material gets hotter, the absorption of the incident light increases. However, the high thermal conductivity of copper prevents the metal from getting hotter, thereby maintaining high reflectivity. Fig. 1 shows aluminum and copper reflectivity.

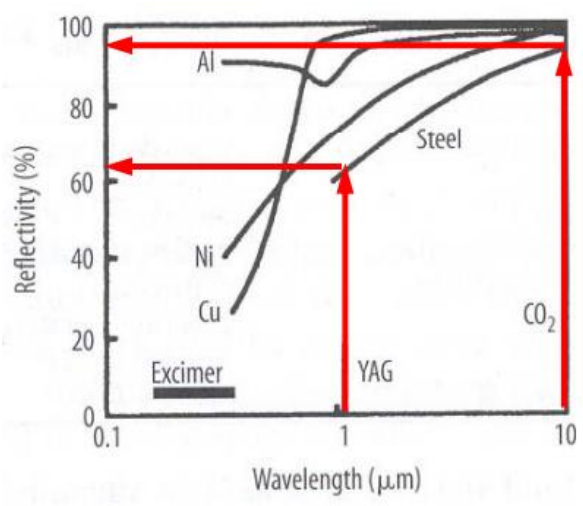

Fig.1 Aluminum and Copper Reflectivity

Laser with hotter wavelength have successfully welded some copper alloys. Copper has slightly higher absorption of the incident light of Nd: YAG lasers with a wavelength of $1.06 \mathrm{Um}$. Plating copper with a thin layer of higher absorbing metal such as nickel has demonstrated to improve coupling efficiency. Generally, nickel alloys and titanium are highly weldable, with aluminum alloys and copper being case specific. The plating material and method of plating can also have a significant effect on the welding process. For example, electro-less nickel plating creates welding problems due to the inclusion of phosphor and other contaminants during the plating process. The recommended plating method is electrolytic. The thickness and type of plating is also a consideration such as coating thickness above 50 micro-inches may induce weld cracking.

\section{Soldering and Brazing:}

\section{Issues With Current Welding Processes}

When copper is brazed to aluminum and the heating process takes too long, the copper will diffuse into the aluminum at the joints. A low melting $\mathrm{Al}-\mathrm{Cu}$ alloy $\left(\mathrm{Al}-\mathrm{Cu} 33\right.$ eutectic temperature $548^{\circ} \mathrm{C}$ ) is thus formatted, and this could lead to erosion by perforation. Therefore, during the brazing process, the flame should never be directly applied to the joint, because the heat should be transferred by conduction through the parts to be brazed. As soon as the filler metal begins to melt, the flame must be quickly removed. A second issue with brazing copper to aluminum is that the aluminum has a much lower melting point than copper ( $\mathrm{Al}$ : app. $650^{\circ} \mathrm{C}$; and $\mathrm{Cu}$ : above $1000^{\circ} \mathrm{C}$ ). Therefore, the flame is usually directed on the copper. Nevertheless, once the heat transferred from the copper to the aluminum reaches the melting range of aluminum, it will start to burn down very fast, while the copper is still taking the heat. The formation of the above mentioned low melting Al-Cu alloy accelerates the destruction of the aluminum components. There are no conventional furnace designs which will cool quickly enough to halt the continual formation of the aluminum-copper eutectic. For this reason, brazing copper to aluminum in a furnace is not practiced.

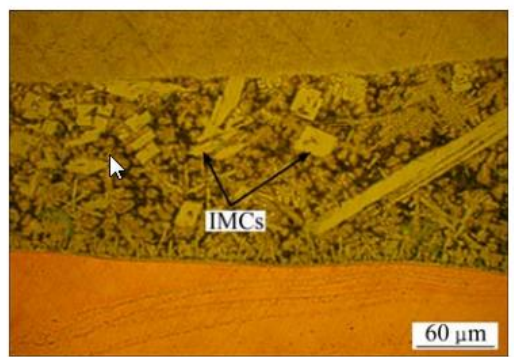

Fig.2 SEM image of brazing seam zone in $\mathrm{Cu} / \mathrm{Al}$ Joined 
XIA et al $[8,9]$ attempted to join $\mathrm{Cu}$ with $\mathrm{Al}$ using vacuum brazing with a eutectic $\mathrm{Al}-\mathrm{Si}$ filler metal, but this technique cannot produce a $\mathrm{Cu} / \mathrm{Al}$ joint with desired property. Micrographs of the $\mathrm{Cu} / \mathrm{Al}$ samples as shown in Fig. 2 at the brazing seam zone display four layers between $\mathrm{Cu}$ and $\mathrm{Al}$, namely, the transition region on the Al side, the middle brazing seam region, the IMC layer and the intermediate layer of saturated solid solution on the $\mathrm{Cu}$ side. The morphology and distribution regularities of the brazing seam microstructure severely affect the shear strength of the $\mathrm{Cu} / \mathrm{Al}$ brazing joint. Moreover, the increased micro hardness of the joint is large due to the formation of the $\mathrm{Al} 2 \mathrm{Cu}$ IMC particles. However, these IMC particles are hard, brittle and can easily become the stress concentration areas in the brazing process when they appear in bulk shape which may become the source of crack initiation and expansion.

\section{Tungsten Inert Gas Welding}

The dissimilar metal welds of aluminium and Copper using TIG shows number of limitations in reliability and strength of joint . low solid solubility and difference in thermal physical properties of aluminium and Copper forms the brittle intermetallic compound which affects the mechanical behaviour of weld. The microstructures of HAZ of aluminium appears to be coarser then the base metal. The strength of joint is found in a range of 500 to $800 \mathrm{~N}$; however it is about 1100- 1200 in the base metal for joint of $1 \mathrm{~mm}$ Copper sheet and $0.8 \mathrm{~mm}$ aluminium sheet. Very brittle intermetallic compounds are formed when metals such as steel, copper, magnesium or titanium are directly arc welded to aluminium.

\section{Gas Metal Arc Welding}

Aluminum is an active metal which reacts with oxygen in the air to produce a hard, thin film of aluminum oxide on the surface. The melting point of aluminum oxide is approximately $3600^{\circ} \mathrm{F}\left(1982^{\circ} \mathrm{C}\right)$ which is almost three times the melting point of pure aluminum $\left(1220^{\circ} \mathrm{F}\left(660^{\circ} \mathrm{C}\right)\right)$. In addition, this aluminum oxide film absorbs moisture from the air, particularly as it becomes thicker. Moisture is a source of hydrogen, which causes porosity in aluminum welds. Hot cracking or solidification cracking is a primary cause for aluminum cracks. As we are all aware aluminum is much weaker than steel and has a much lower weld solidification temperature. These cracks typically occur due to thermal expansion and contraction. The resulting stresses may tear the weld apart.

\section{Friction Stir welding}

A longer friction time caused the excess formation of an intermetallic layer. However, some of the welds showed poor strength depending on some accumulation of alloying elements at the interface, which are the result of a temperature rise and the existence of intermetallic layers such as Fe-Al Although tensile strength for copper and aluminium joints were generally accepTable when compared with those of the base metals, some of the welds showed poor strength as a result of the accumulation of alloying elements at the interface. This was the result of temperature Mechanical and Metallurgical Properties of Friction Welded Aluminium Joints rise and the existence of a grey layer. This grey layer formed due to heat dissipation in friction welding and was found to contain a considerable amount of intermetallic compounds The presence of contaminants at the interface of the metals reduces the joint quality. No significant effect was observed on welding properties with respect to the surface finish operations.

\section{Selection Of Laser Welding Parameters}

In This study Nd:YAG diode pumped laser (Maximum power, 4.4kW) is used specifically for copper and aluminum. We have selected laser power, welding speed and position of focal plane of the beam with respect to the surface of work piece as main parameters based on capability of laser welding machine. Output of the experiment is measured in the terms of weld penetration, tensile strength of the joint to evaluate the laser welding experiments.

\section{Experimental Work}

In this study Nd:YAG diode pumped laser (Maximum power, $4.4 \mathrm{~kW}$ ) is used. The experiment was designed based on a three level Full factorial design Laser power (1.2 - $1.43 \mathrm{~kW})$, welding speed $(30-70$ $\mathrm{cm} / \mathrm{min})$ and focal point position $(-2.5-0 \mathrm{~mm})$ being the laser independent input variables. Laser beam diameter is kept constant which is $0.2 \mathrm{~mm}$. Table 1 shows laser input variables and experimental design levels used. RSM was applied to the experimental data using statistical software, Minitab-16. We have considered full factorial design as shown in Table-1 of experiments to generate regression equation for further study and conclusion from experiment. 
Table 1: Full Factorial Design

\begin{tabular}{|c|c|c|c|}
\hline & \multicolumn{3}{|c|}{ Full Factorial Design 2X3 } \\
\hline Sr. No. & Laser power & welding speed & focal position \\
\hline 1 & 1.43 & 70 & -2.5 \\
\hline 2 & 1.2 & 70 & 0 \\
\hline 3 & 1.43 & 30 & 0 \\
\hline 4 & 1.43 & 30 & -2.5 \\
\hline 5 & 1.2 & 70 & -2.5 \\
\hline 6 & 1.43 & 70 & 0 \\
\hline 7 & 1.2 & 30 & -2.5 \\
\hline 8 & 1.2 & 30 & 0 \\
\hline
\end{tabular}

Table 2: Laser parameters and variables

\begin{tabular}{|l|c|c|c|c|}
\hline & \multicolumn{2}{|c|}{ Aluminum } & \multicolumn{2}{c|}{ Copper } \\
\hline & Min & Max & Min & Max \\
\hline Power (Kw) & 2 & 3 & 3 & 4 \\
\hline Speed (mm/min) & 540 & 660 & 720 & 900 \\
\hline
\end{tabular}

In this experimentation 4KW Nd:YAG laser was used for welding of Copper and aluminum in butt joint arrangement. Burr and oxides present over specimen are grinded by grinding wheel before proceeding for welding. The desired surface finish was achieved by adjusting sampled to their proper dimensions. all the samples were cleaned by washing the same by diesel to remove any greasing and contamination to improve absorptivity of the laser on the sample surface. Table 2 shows parameter level for experimental work. Laser welding is carried out MOGOD Fusion Technologies, Bhosari MIDC, Pimpri Chinchwad. Laser welding setup is consist of highly precise robot which controls speed of welding. At the tip of the robot, welding head is mounted. Laser welding head as shown in Figs. 3 and 4 is stack of optical lenses by centerline lasers. Laser is pumped though a power source situated remotely away from the work facility.

\section{Experimental Setup:}

Copper and aluminum plates are clamped firmly to maintain $0.2 \mathrm{~mm}$ of gap between two plates as below with the help of jig and fixture setup as shown in Figs. 4 and 5. Both Plates are dimensioned $70 \mathrm{mmx} 70$ $\mathrm{mm} \times 2 \mathrm{~mm}$. Copper plates are nickel plated to reduce the reflectivity of surface and increase heat conduction rate. Plates are also grinded at their edges to achieve minimum clearance requirement criteria.

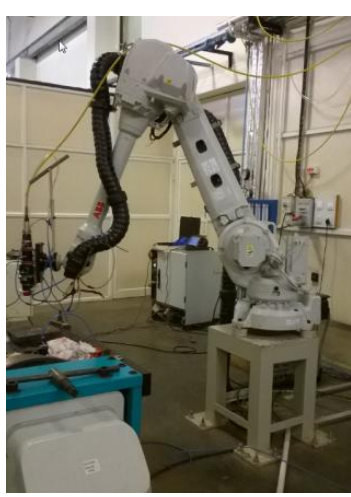

Fig.3 laser welding robot

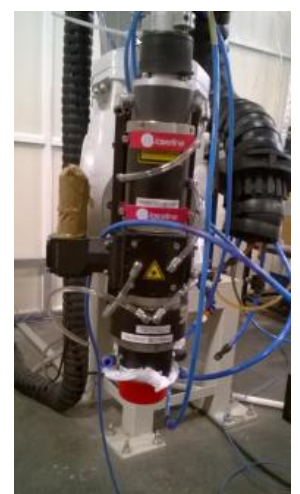

Fig.4 Laser welding head 

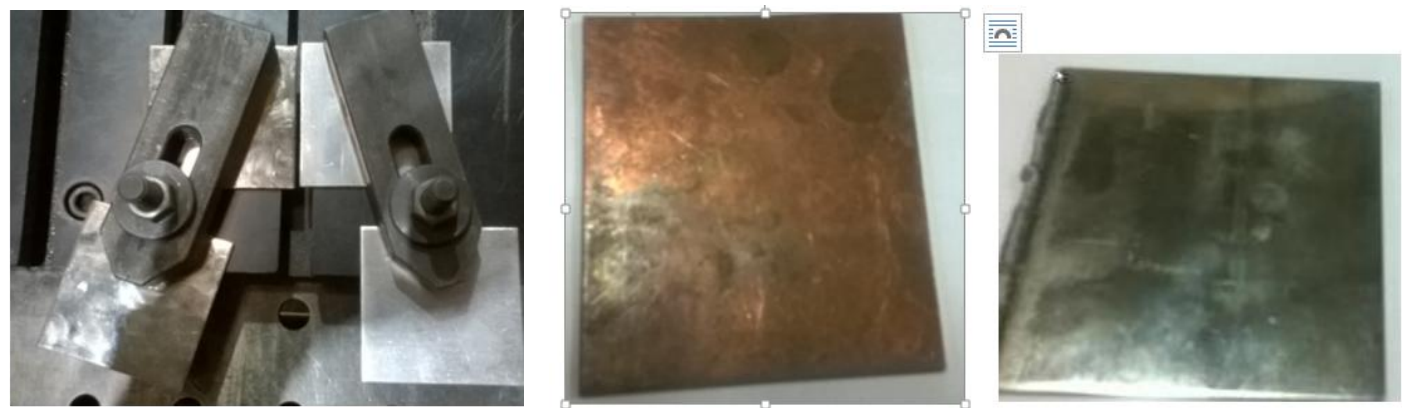

Fig.5 Fixture setup and raw copper plates before and after plating

\section{Experiment-1:}

Initially laser weld trials are carried out with copper and aluminum joint without using filler materials. Parameters noted during initial trials are -

- $\quad$ Power $=4 \mathrm{kw}$

- $\quad$ Speed $=900 \mathrm{~mm} / \mathrm{min}$

- $\quad$ Nozzle gas $=10 \mathrm{lpm}$

Pre-weld is carried out focusing on Copper side initially to generate heat as copper required higher heat for melting compared to Aluminum. Then the beam dia. is spotted on aluminum part for initiating aluminum plate welding. It is observed that when percentage of spot coverage on aluminum side is higher or same as heat requirement for copper, aluminum cannot sustain equal amount of power and metal burning is observed on aluminum side along with stitched weld pattern. Experiment is repeated with spotting the laser weld spot diameter percentage more on copper plate side. This time spot was $70 \%$ on coper plate and $30 \%$ on Aluminum plate. This has given good results compared to previous case as copper gets higher amount of power for melting down metal and form fusion zone. It has been observed that joint without filler material is very susceptible to solidification cracks due to higher intermetallic observed. Porosity is also very high showing the granular structure at the weld. Weld joint did not survive the pickup load and drop test ended up with sever cracks. Figs. 6 and 7 shows joint after weld.

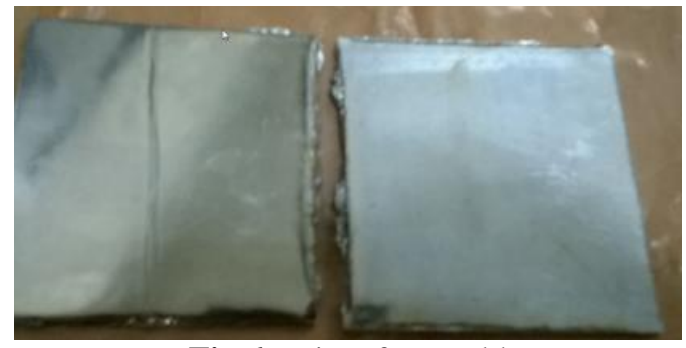

Fig.6: Joint after Weld
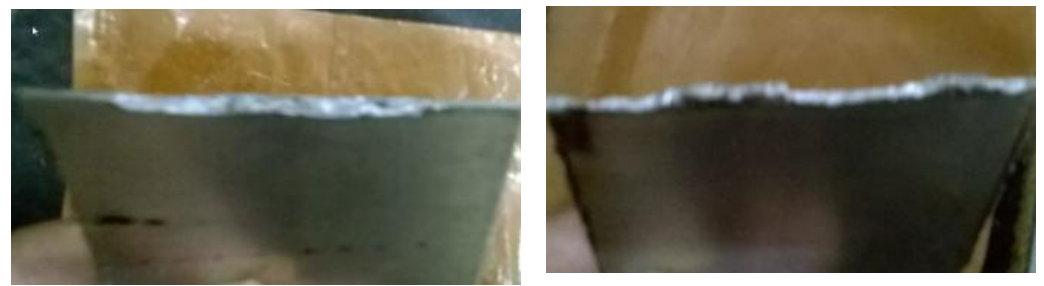

Fig.7 Aluminum plate after weld Copper plate after weld

\section{Experiment-2:}

Considering observations from first experiment regarding solidification cracking which happened immediately as weld cools down, it has been concluded that copper and Aluminum needs filler material to create fusion weld and minimize Intermetallic structure. Thus it has been decided to carryout second experiment using intermediate filler material in powder form. from studies it is prominent that powder will help create better fusion joint allowing both copper and aluminum to fuse with respective metal present in filler material. The aluminum base alloys are highly crack sensitive because they contain approximately $1.0 \%$ Magnesium Silicide (Mg2Si), which falls close to the peak of the solidification crack curve. It is often possible to produce a weld, 
particularly on corner joints, by melting both edges of the base material together without adding filler material when we laser weld on thin materials are laser welded. To obtain continuous crack free welds, it is recommended to add filler material during the weld. To reduce crack sensitivity, filler alloy 2036 is added to all welds during welding in order. Below are the parameters set for carrying out experimentation-

- $\quad$ Power $=4 \mathrm{kw}$

- $\quad$ Speed $=900 \mathrm{~mm} / \mathrm{min}$

- Nozzle gas= $10 \mathrm{lpm}$

- Pass: Single Pass

To avoid metal burning, experiments were carried out with two different pulse on and off frequency 8 ms ON 3 $\mathrm{ms}$ OFF and $5 \mathrm{~ms}$ ON and $3 \mathrm{~ms}$ OFF. Figs.. 8 and 9 are the copper and aluminum welding with separate pulse duration-

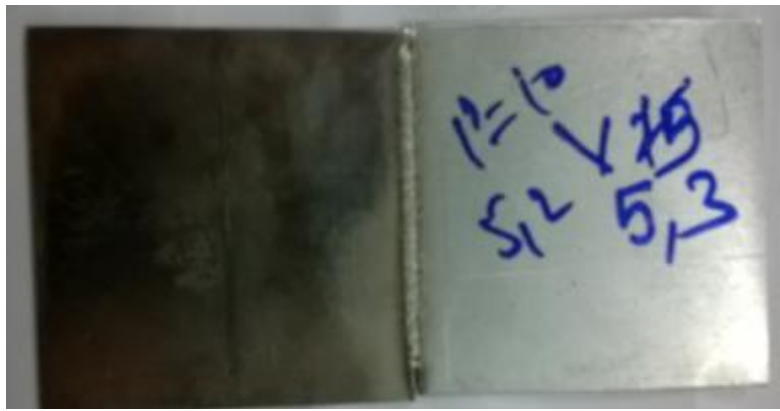

Fig.8: Pulse ON/OF 5/3 ml-sec

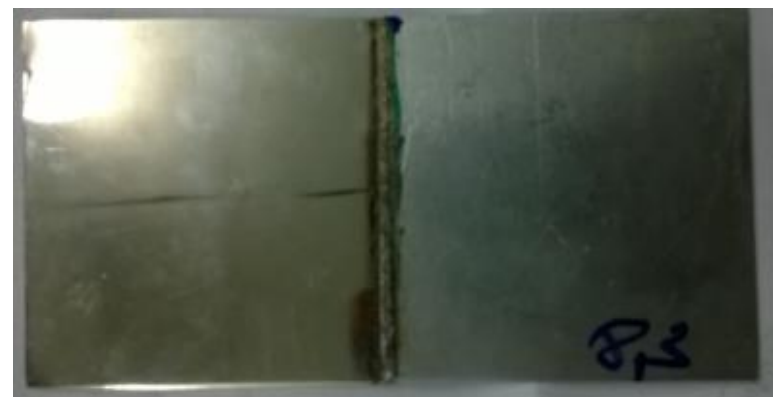

Fig.9: Pulse: ON/OF 8/3 ml-sec

\section{Observations:}

- $\quad$ Specimen with pulse frequency of 5-3 are observed to be more strengthener than 8-3.

- High Intermetallic were observed after weld solidification

- Cracks were also observed internally visually after cooling

- Joint has manually tested for drop test and it is sustaining the Drop test

- When samples are sent for metallurgical analysis, Joint failed during sample preparation

\section{Experiment-3:}

As silicon has very good compatibility with copper and aluminum [4], silicon based Al-si alloy filler material are applied. In particular the filler alloys AlSi12 is used, which is standardized materials for thermal welding and brazing processes and available in wire form in market. Table 2 shows properties of filler material.To use Filler material both specimen plate under weld are prepared to form $\mathrm{V}$ groove to hold filler material correctly. Specimen plates are kept at a distance and clamped firmly to hold filler wire at its position during weld. It is observed that if filler wire is not placed firmly, it gets dislocated due to thermal distortions. Thus it is recommended that filler wires also can be tag welded first at two or more location and should be followed by continuous weld. Fig. 10 shows experimental clamping setup for filler material.

Table.3: Properties of filler material 


\begin{tabular}{|l|l|l|l|l|}
\hline & CU-OFE & Al 99,5 & CuSi3 & AlSi12 \\
\hline $\begin{array}{l}\text { melting point } \\
\text { in }{ }^{\circ} \mathrm{C}\end{array}$ & 1083 & 660 & 965 & 575 \\
\hline $\begin{array}{l}\text { boiling point } \\
\text { in }{ }^{\circ} \mathrm{C}\end{array}$ & $\begin{array}{l}2600 \\
\text { (approx.) }\end{array}$ & $\begin{array}{l}2450 \\
\text { (approx.) }\end{array}$ & $\mathrm{n} / \mathrm{a}$ & $\mathrm{n} / \mathrm{a}$ \\
\hline $\begin{array}{l}\text { tensile strength } \\
\text { in } \mathrm{N} / \mathrm{mm}^{2}\end{array}$ & 290 & 150 & 350 & 100 \\
\hline $\begin{array}{l}\text { breaking elongation } \\
\text { in } \%\end{array}$ & 33 & 25 & 40 & 5 \\
\hline $\begin{array}{l}\text { thermal expansion } \\
\text { in } 10^{-8} / \mathrm{K}\end{array}$ & 17,7 & 23,5 & 18 & 20 \\
\hline $\begin{array}{l}\text { thermal conductivity } \\
\text { in } \mathrm{W} / \mathrm{m}^{*} \mathrm{~K}\end{array}$ & 400 & 220 & 35 & 160 \\
\hline $\begin{array}{l}\text { electric conductivity } \\
\text { in } \mathrm{S}^{*} \mathrm{~m} / \mathrm{mm}^{2}\end{array}$ & 56 & 34 & 3 & 17 \\
\hline
\end{tabular}

Fig.10: Experimental clamping setup for Filler material

Below are the weld parameters set during the process. Laser welding for this experiment is completed with two passes. One is for Copper and Filler wire at $4 \mathrm{KW}$ and other is with Aluminum and Filler wire at $2 \mathrm{KW}$. Two passes helps in setting two different parameter setting for per metals suitability, which ensures perfect fusion between two dissimilar metals.

- Copper Power= $4 \mathrm{kw}$

- Aluminum power $=2 \mathrm{kw}$

- $\quad$ Copper Speed $=900 \mathrm{~mm} / \mathrm{min}$

- Aluminum Speed $=450 \mathrm{~mm} / \mathrm{min}$

- Nozzle gas $=10 \mathrm{lpm}$

- Weld Pass: 2 Passes

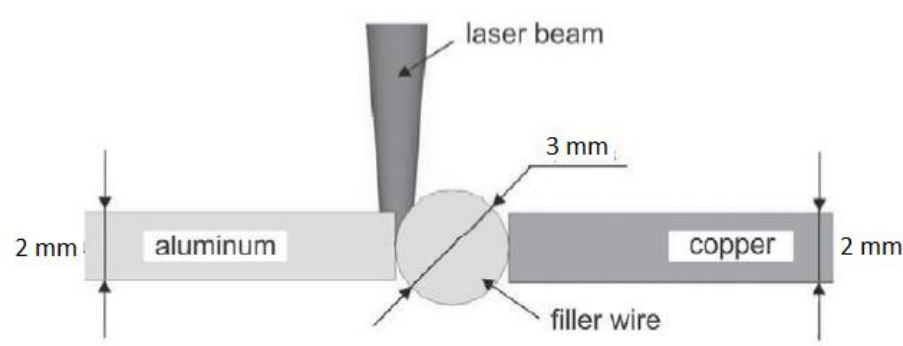

Fig.11: Schematic aluminum and copper plates with filler wire

Filler wire of diameter $3 \mathrm{~mm}$ is chosen to ensure sufficient joining gap and increased exposure of laser radiation especially on copper side at the joining area to be realized. For ensuring efficient joint, on each side of connection four weld spots with pitch of $2 \mathrm{~mm}$ are placed. Effect of atmospheric gases on fused material is avoided by using inert shielding gas Argon with flow rate of 7 1/min. Fig.12 shows final weld specimen of copper and aluminum. After the welding process the down holders of the clamping device can be disengaged, making the samples available for further examinations. 

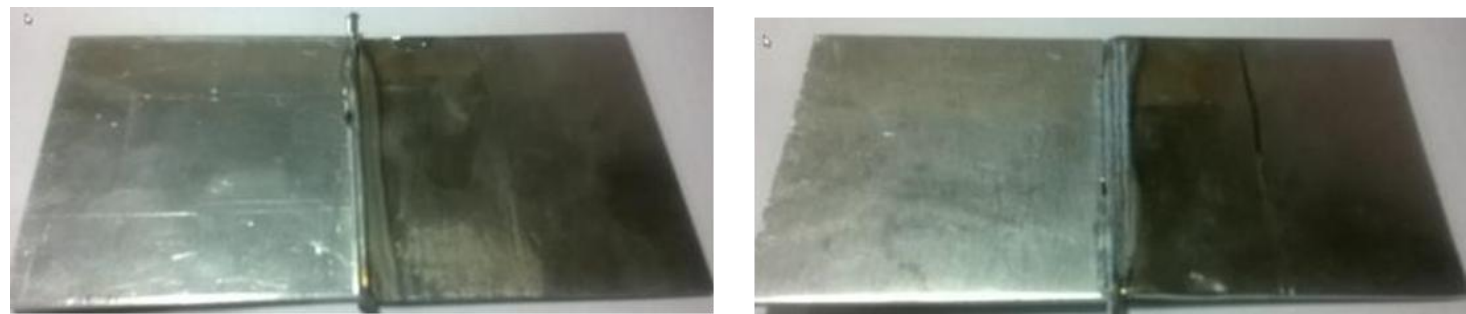

Fig.12: Final welded specimen of copper and aluminum

\section{Observations for Copper and aluminum joint:}

- Silicon contain in aluminum plays significant role in welding with other dissimilar metals like Copper

- It is very difficult to weld copper and aluminum without filler material or with nickel filler powder

- Negligible intermetallic were observed in a joint with Al-Si12 filler wire

- Joint has went under Drop test from $6 \mathrm{ft}$ height and joint sustained the drop test successfully

- Joint sustained sample preparation

\section{RESULTS And Discussion}

Micrograph of Filler wire and aluminum plate cross section is shown in Fig.13. Observations for Aluminum plate is- Pin holes, blow holes and porosity observed at weld. Complete root fusion observed. Complete side wall fusion observed.
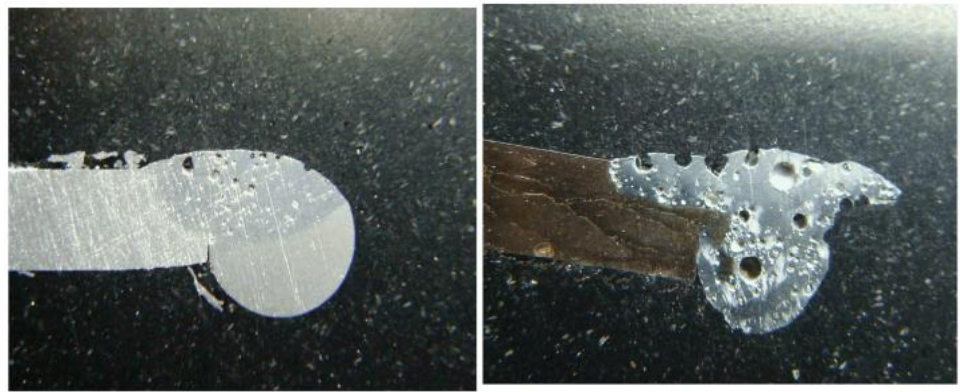

Fig.13: Weld Penetration Test for Aluminum Plate and Copper plate

For Copper plate, as shown in Fig. 13: Pin holes, blow holes and porosity observed at weld. Complete root fusion observed. Complete side wall fusion observed.

Moreover a good weld of the cross-sectional area without any porosity or cracking with filler material is observed. Increase in element intermixture can be detected at welds with Alsi12 filler materials effect is more prominent with filler. Hence it can be noted, that the element silicon leads to a lower viscosity of the molten metal and an enhancement of the melt pool turbulence.

\section{Conclusion}

- In review of Optimizing Laser welding parameters for Copper and Aluminium joint, current issues with welding aluminium and copper by TIG, MIG, Brazing and Friction stir welding process has been identified.

- From experiment one, it is concluded that, Copper and Aluminium 6061 grades are very difficult to lap weld with LBW because of higher intermetallic due to different solidification rate.

- Plating copper with Nickel has no effect on welding output with aluminium. Outcome is observed as same with and without nickel plating.

- From second experiment, it is also concluded that filler alloy 2036 do not have weld fusion for copper and aluminum. Silicon content is only factor which creates fusion between these dissimilar metals.

- From third experiment it is evident that Silicon content in Aluminum plays Major role in welding Copper and Aluminum

- Electrode grade Copper and Aluminium 6061 can be successfully welded using Filler wire AlSi12 by maintaining stringent process and fixturing

- Aluminium 4047 grade is identified as most suiTable material for welding with copper

- CuPower and Cuspeed is identified as significant parameter for achieving higher tensile strength with Filler wire. 
[1] R. K. Roy ,Design of Experiments Using The Taguchi Approach: 16 Steps to Product and Process Improvement, 16(2), 2013, 3-5

[2] M. Harooni, Studying the Effect of Laser Welding Parameters onthe Quality of ZEK100 Magnesium Alloy Sheets in Lap Joint Configuration, 18(1)2012, 539-548

[3] M. M. Hailat, A. Mian, Z.A. Chaudhury, G. Newaz, R. Patwa , H. J. Herfurth,,Laser micro-welding of aluminum and copper with and without tin foil alloy, 18(6), 2012, 103-112

[4] T.A. Mai, A.C. Spowage, Characterization of dissimilar joints in laser welding of steel-kovar, copper-steel and copper-aluminium, Materials science and Engineering, Elsevier ltd, 374(9), 2004, 224-233

[5] A.P. Tadamalle, Reddy, Y.P.a, Ramjee, Influence of laser welding process parameters on weld pool geometry and duty cycle, Advances in Production Engineering \& Management Journal, 215(15), 2013, 114-134

[6] H. R. kim, K. Y. Lee, Hyundai heavy industries co. 1td, Application of Taguchi method to determine hybrid welding condition of aluminum alloy, Journl of Scientific Industrial research, 6(7), 2014, 145-150.

[7] K. Kalaiselvan, A. Elango, N. M. Nagarajan, Comparative Studies on Dissimilar Metals thin Sheets Using Laser Beam Welding, International Journal of Mechanical, Aerospace, Industrial, Mechatronic and Manufacturing Engineering 8(10), 2014, 1754-1755

[8] V. Chauhan Assistant Professor, Role Pf Taguchi Design of Experiment in optimization of welding process parameters for different Material , International Journal of Advanced Technology \& Engineering Research (IJATER), 17(7), 2014, 689-701

[9] J.F. Guo, H.C. Chen, C.N. Sun, G. Bi, Z. Sun, J. Wei, Friction stir welding of dissimilar materials between AA6061 and AA7075 Al alloys effects of process parameters, Materials and Design 5(9), 2014, 185-192.

[10] Y. Bozkurt, M. K. Bilici, Application of Taguchi approach to optimize of FSSW parameters on joint properties of dissimilar AA2024-T3 and AA5754-H22 aluminum alloys, Materials and Design 51(4), 2013, 513-521

[11] M. H. Tolephih, K. M. Mashloosh, Z. Waheed, Comparative Study of the Mechanical Properties of (FS) and MIG Welded Joint in (AA7020-T6) Aluminum Alloy,Al-Khwarizmi Engineering Journal, 7(2), 2011, 22 - 35

[12] G H. Gowd, E V. Goud, Analysis of Performance Characteristics of Laser BeamWelding,International Journal of Engineering Science and Technology (IJEST), 0 4(05), 2012, 1925

[13] G. Phanikumar, S. Manjini, P. Dutta, J. Mazumder, and K. Chattopadhyay, Characterization of a Continuous CO2 Laser-Welded Fe-Cu Dissimilar Couple, Metallurgical And Materials Transactions A, 36(16), $2005,2137$. 